\title{
Validity of prepartum changes in vaginal and rectal temperature to predict calving in dairy cows
}

\author{
O. Burfeind, V. S. Suthar, R. Voigtsberger, S. Bonk, and W. Heuwieser ${ }^{1}$ \\ Clinic for Animal Reproduction, Faculty of Veterinary Medicine, Freie Universität Berlin, Koenigsweg 65, 14163 Berlin, Germany
}

\begin{abstract}
The prevalence of dystocia is high in many dairy herds and is associated with stillbirth and negative effects for the cow. An accurate predictor of calving would enable supervision of cows more precisely to a relevant time interval so that obstetrical assistance can be provided in a timely manner. This might help to decrease calf mortality rate. Evidence exists that cows exhibit a decrease in body temperature before the onset of calving. The performance of a decrease in body temperature as a test to predict the onset of calving in dairy cows has not been investigated. The objective was to investigate test criteria of a decrease in vaginal and rectal temperature as predictors of calving in dairy cows. In 3 experiments, temperature loggers (Minilog 8, Vemco Ltd., Halifax, Canada) were inserted into the vagina of cows before calving $(\mathrm{n}=85)$, and rectal temperatures were measured twice daily in 55 of these cows. Vaginal temperatures were 0.2 to $0.3^{\circ} \mathrm{C}$ and 0.6 to $0.7^{\circ} \mathrm{C}$ lower on the day of calving compared with 24 and $48 \mathrm{~h}$ before calving, respectively. Rectal temperatures were 0.3 to $0.5^{\circ} \mathrm{C}$ and 0.4 to $0.6^{\circ} \mathrm{C}$ lower on the day of calving compared with 24 and $48 \mathrm{~h}$ before calving, respectively. Vaginal temperatures exhibited a diurnal rhythm during the $120 \mathrm{~h}$ before calving, which continued on a lower level during the $48 \mathrm{~h}$ preceding parturition. In the 3 experiments, a decrease in vaginal temperature of $\geq 0.3^{\circ} \mathrm{C}$ over $24 \mathrm{~h}$ could predict calving within $24 \mathrm{~h}$, with sensitivity ranging from 62 to $71 \%$ and specificity ranging from 81 to $87 \%$. Similarly, a decrease in rectal temperature measured at $0730 \mathrm{~h}$ of $\geq 0.3^{\circ} \mathrm{C}$ could predict calving within $24 \mathrm{~h}$, with sensitivity from 44 to $69 \%$ and specificity from 86 to $88 \%$. Although dairy cows exhibit a distinctive decrease in vaginal and rectal temperatures commencing approximately $48 \mathrm{~h}$ before calving, detecting this decrease does not determine the onset of calving precisely. Nevertheless, it can provide valuable information in addition to
\end{abstract}

Received April 26, 2011.

Accepted June 23, 2011.

${ }^{1}$ Corresponding author: heuwieser.wolfgang@vetmed.fu-berlin.de the traditional signs (i.e., relaxation of the sacrosciatic ligament) that calving is imminent.

Key words: dairy cow, body temperature, parturition, test performance

\section{INTRODUCTION}

Body temperature in cattle exhibits a circadian rhythm with a minimum temperature in the morning and a maximum temperature in the late afternoon (Piccione et al., 2003; Kendall and Webster, 2009). Several variables influence body temperature and the pattern of the circadian rhythm, such as windy and rainy weather conditions (Webster et al., 2008), heat stress (Kendall et al., 2006), the effectiveness of cooling methods (Kendall et al., 2007), and milking frequency (Kendall et al., 2008). Furthermore, physiological status (e.g., estrus, pregnancy, lactation) influences the diurnal temperature pattern of dairy cows (Piccione et al., 2003; Kendall and Webster, 2009; Suthar et al., 2011).

Prevalence of dystocia in dairy cows remains high. Mee (2008) reviewed the international prevalence of dystocia, which ranged from 3 to $22.6 \%$ in primiparous and 1.5 to $13.7 \%$ in primiparous and multiparous cows. The reported prevalence of dystocia was higher in 2 studies in the United States. Dystocia ranged from $28.6 \%$ (Meyer et al., 2001) to $51.2 \%$ (Lombard et al., 2007 ) in primiparous cows and from $10.7 \%$ (Meyer et al., 2001) to $29.4 \%$ (Lombard et al., 2007) in multiparous cows. The occurrence of dystocia was associated with increased mortality of newborn calves (Tenhagen et al., 2007) and with negative effects on both dam and offspring (Lombard et al., 2007; Tenhagen et al., 2007 ). Although in one study only $10.8 \%$ of calves were delivered by a dam with severe dystocia, these calves accounted for $49.1 \%$ of all stillbirths (Lombard et al., 2007). The duration of the second stage of labor and the presentation, position, and posture of the fetus were key risk factors for perinatal mortality in dairy calves (Gundelach et al., 2009). Furthermore, dystocia was negatively associated with milk yield (Rajala and Gröhn, 1998), fertility (e.g., cumulative pregnancy rate at 200 DIM), and survival of the dam (Tenhagen et al., 2007). 
Shah et al. (2006) hypothesized that predicting the onset of calving may potentially help to ensure the integrity of newborn calves and cows in difficult birth situations. Furthermore, Mee (2004) speculated that good supervision during stage 2 of calving might reduce dystocia due to prolonged calving and thus reduce perinatal mortality. Therefore, much effort has been made to identify measures that predict calving in cows. Birgel et al. (1994) found that 21 of 23 cows observed calved within $22 \mathrm{~h}$ after serum progesterone concentration decreased to $<1.5 \mathrm{ng} / \mathrm{mL}$. In that study, relaxation of the sacrosciatic ligament predicted calving within $22 \mathrm{~h}$ in 12 out of 23 cows, whereas a decrease in rectal temperature (RT) of $\geq 0.4^{\circ} \mathrm{C}$ measured thrice daily predicted calving in only 10 cows. In another study, the relaxation of the sacrosciatic ligament was measured objectively. An incremental relaxation of the ligament by $\geq 5 \mathrm{~mm}$ predicted calving within $24 \mathrm{~h}$ in 31 out of 37 cows (Shah et al., 2006). Test characteristics were not described in these studies.

Evidence exists that cows of beef breeds exhibit a decrease in body temperature before the onset of parturition (Lammoglia et al., 1997; Aoki et al., 2005; Cooper-Prado et al., 2011). Lammoglia et al. (1997) reported that diurnal variation in body temperature was absent during a period from 48 to $8 \mathrm{~h}$ before parturition. Furthermore, Aoki et al. (2005) showed that parturition occurred within $36 \mathrm{~h}$ after a decrease in vaginal temperature $(\mathbf{V T}) \geq 0.3^{\circ} \mathrm{C}$ between a particular time of the day and the same time of the preceding day in 23 out of 31 cows by measuring VT continuously.

Information on the test performance of changes in body temperature to predict calving in dairy cows is lacking. Therefore, the objective was to determine the test performance (sensitivity, specificity, positive and negative predictive values) of decreases in VT and RT as predictors of calving in dairy cows.

\section{MATERIALS AND METHODS}

The first experiment was conducted between April and October 2009 at the University of British Columbia Dairy Education and Research Centre (Agassiz, British Columbia, Canada). Animals were managed according to the guidelines set by the Canadian Council of Animal Care (1993). A total of 33 primiparous Holstein cows were used. They were housed in group pens with sand-bedded freestalls. Cows were moved to the maternity pen (sand-bedded box stall covered with straw) when they showed signs of the onset of parturition (i.e., restlessness, relaxation of the sacrosciatic ligament). They were fed once daily (at approximately $0800 \mathrm{~h}$ ) with a TMR consisting of $44.3 \%$ alfalfa hay, $32.4 \%$ corn silage, and $23.3 \%$ concentrate and min- eral mix on a DM basis. Feed was pushed up several times daily. Vaginal temperature was measured every minute with a microprocessor-controlled temperature data logger (Minilog 8, Vemco Ltd., Halifax, Canada) as previously described and validated (Vickers et al., 2010). The temperature data loggers were attached to a modified controlled internal drug release device without progesterone (CIDR, InterAg, Hamilton, New Zealand) and inserted into the vaginal cavity $6 \pm 2 \mathrm{~d}$ before predicted calving date. During the process of calving, the temperature loggers were expelled from the vaginal cavity. Temperature data were downloaded after calving.

The second and third experiments were conducted between May and July 2010 and in October 2010, respectively, on a commercial dairy farm in SachsenAnhalt, Germany. Cows were managed according to the guidelines set by the International Cooperation on Harmonisation of Technical Requirements for Registration of Veterinary Medicinal Products (Hellmann and Radeloff, 2000). Cows were housed in group pens with deep-straw bedding until calving. A TMR was delivered once daily (at approximately $0700 \mathrm{~h}$ ). In experiment 2 , the TMR consisted of $40.0 \%$ corn silage, $23.7 \%$ grass silage, $4.9 \%$ grass hay, $4.9 \%$ barley straw, and $26.5 \%$ concentrate mineral mix on a DM basis. In experiment 3 , the TMR consisted of $41.7 \%$ corn silage, $21.0 \%$ grass silage, $5.2 \%$ grass hay, $5.2 \%$ barley straw, and $26.9 \%$ concentrate mineral mix on a DM basis. Feed was pushed up several times daily. A total of 38 and 30 multiparous Holstein cows were used in experiments 2 (parity: $3.0 \pm 1.4)$ and $3(3.2 \pm 1.7)$, respectively. Loggers were inserted $8 \pm 4 \mathrm{~d}$ and $9 \pm 4 \mathrm{~d}$ before predicted calving date in experiments 2 and 3, respectively, and measured VT every 10 min. Rectal temperature was measured twice daily $(0730 \mathrm{~h} \pm 15 \mathrm{~min}$ and $1700 \mathrm{~h} \pm$ $15 \mathrm{~min}$ ) in these experiments with the same type of thermometer (Microlife VT 1831, Microlife AG, Widnau, Switzerland) at the same insertion depth $(8 \mathrm{~cm})$ and at the same time of the day to minimize any bias due to the measuring process (Burfeind et al., 2010). During the process of calving, the temperature loggers were expelled from the vaginal cavity. Thus, a sudden decrease in measured temperature was observed and this hour was defined as the hour of calving.

During the course of all experiments, ambient temperature $\left(\mathbf{A T},{ }^{\circ} \mathrm{C}\right)$ and relative humidity $(\mathbf{R H}, \%)$ were recorded hourly using a Tinytag Plus II logger (Gemini Data Loggers Ltd., Chichester, West Sussex, UK) secured on a beam $3 \mathrm{~m}$ from the ground within the experimental pen. The temperature-humidity index (THI) was calculated according to the equation reported by Kendall et al. $(2008)$ : $\mathrm{THI}=(1.8 \times \mathrm{AT}+$ $32)-[(0.55-0.0055 \times \mathrm{RH}) \times(1.8 \times \mathrm{AT}-26)]$. 
All data were statistically analyzed with SPSS (version 18.0, SPSS Inc., Munich, Germany) and MedCalc software (version 10.1.3.0, Medcalc, Mariakerke, Belgium). Vaginal temperature was measured every $1 \mathrm{~min}$ (experiment 1 ) or every $10 \mathrm{~min}$ (experiments 2 and 3 ). For further analysis, hourly means were calculated for every cow independently. Vaginal temperatures below $38.0^{\circ} \mathrm{C}$ were considered as artifacts due to loss or movement of the temperature logger and excluded from further analysis. Relationships between RT, VT, and THI were calculated with Pearson correlation. Differences between RT and VT were determined with a paired $t$ test comparing the corresponding values. Differences in $\mathrm{VT}$ between the day of calving and $3 \mathrm{~d}$ antepartum were compared using repeated-measures ANOVA. Similarly, differences in VT among the last $99 \mathrm{~h}$ before calving were compared using repeated-measures ANOVA. The analysis was restricted to $99 \mathrm{~h}$ due to limitations of the SPSS software. Similarly, differences in RT between the day of calving and $5 \mathrm{~d}$ antepartum were compared using repeated-measures ANOVA.

The difference between VT at a particular time of day and VT at the same time 24 and $48 \mathrm{~h}$ previously was calculated for the last $120 \mathrm{~h}$ before calving. The diagnostic performance of a decrease in VT and RT to predict calving within the next $24 \mathrm{~h}$ was tested using receiver-operating characteristics (ROC) analysis for both the 24-h and the 48-h differences. The continuous variable was the difference in VT or RT, respectively, and the classification variable was the occurrence of calving within $24 \mathrm{~h}$. Because VT was measured continuously, calculated differences were available for $24 \mathrm{~h} / \mathrm{d}$. Therefore, 24 positive events, defined as the occurrence of calving within $24 \mathrm{~h}$, existed per cow. Similarly, only 1 positive event existed per cow comparing differences of $\mathrm{RT}$ in the morning or the evening, respectively. Means and $95 \%$ CI were calculated for the test characteristics (sensitivity, specificity, positive and negative predictive values). Sensitivity was defined as the proportion of positive events (occurrence of calving within $24 \mathrm{~h}$ ) correctly predicted by the test (decrease of VT or RT, respectively). Specificity was defined as the proportion of negative events (absence of calving within $24 \mathrm{~h}$ ) correctly diagnosed as negative by the test (no decrease in VT or RT, respectively). The positive predictive value was determined as the proportion of events at which the cows showed a decrease in temperature and calved within $24 \mathrm{~h}$. The negative predictive value was calculated as the proportion of events at which the cows did not show a decrease in temperature and did not calve within $24 \mathrm{~h}$. The predictive values were calculated based on the apparent prevalence (calving within $24 \mathrm{~h}$ in relation to all events) in the 3 study populations.

\section{RESULTS}

Daily ambient temperatures (mean $\pm \mathrm{SD}$ ) were 15.7 $\pm 5.2^{\circ} \mathrm{C}, 21.9 \pm 5.5^{\circ} \mathrm{C}$, and $11.1 \pm 3.5^{\circ} \mathrm{C}$ in experiments 1,2 , and 3 , respectively, whereas THI were $59.6 \pm 7.0$, $68.0 \pm 7.1$, and $52.5 \pm 5.7$. Vaginal temperature and THI were correlated (experiment 1: $\mathrm{r}=0.12$; experiment $2: \mathrm{r}=0.25$; experiment $3: \mathrm{r}=0.20 ; P<0.05)$. Rectal temperature was correlated with THI (experiment $2: \mathrm{r}=0.33$; experiment $3: \mathrm{r}=0.22 ; P<0.05$ ). Rectal temperature and VT were correlated in experiment $2(\mathrm{r}=0.89 ; \mathrm{n}=441 ; P<0.05)$ and experiment $3(\mathrm{r}=0.76 ; \mathrm{n}=414 ; P<0.05)$. Vaginal temperature was higher than RT in experiment $2\left(0.1 \pm 0.2^{\circ} \mathrm{C} ; \mathrm{n}=\right.$ 441; $P<0.01)$ and experiment $3\left(0.2 \pm 0.2^{\circ} \mathrm{C} ; \mathrm{n}=414\right.$; $P<0.01)$.

In the first experiment, 3 cows were excluded from analysis because the temperature logger was inserted into the vaginal cavity less than $3 \mathrm{~d}$ before parturition. Therefore, data from 30 heifers were used for final analysis. Mean age at first calving was $25.0 \pm 1.7 \mathrm{mo}$ and gestation length $279 \pm 5 \mathrm{~d}$. In experiment 1, 154 of 245,124 measures of $\mathrm{VT}(<0.1 \%)$ were $<38.0^{\circ} \mathrm{C}$ and excluded from further analysis.

In the second and third experiments, data from 8 and 5 cows, respectively, were excluded from analysis because the cows calved within $3 \mathrm{~d}$ of insertion of the temperature logger. Therefore, data from 30 and 25 cows, respectively, were used for the final analysis in experiments 2 and 3. Mean calving interval was $399 \pm$ $88 \mathrm{~d}$ and $406 \pm 84 \mathrm{~d}$ and gestation length was $281 \pm 4$ $\mathrm{d}$ and $281 \pm 3 \mathrm{~d}$ in experiments 2 and 3 , respectively. In experiment 2, 595 of $34,134(1.7 \%)$ and in experiment 3,244 of $31,062(0.8 \%)$ measures of VT were $<38.0^{\circ} \mathrm{C}$ and excluded from further analysis. Mean VT was lower on the day of calving compared with 1,2 , and $3 \mathrm{~d}$ antepartum in all experiments (Table 1, Figure 1). On an hourly basis, VT started to decrease approximately 48 , 36 , and $48 \mathrm{~h}$ before parturition in experiments 1,2 , and 3 , respectively (Figure 1). Vaginal temperature reached a nadir $18 \mathrm{~h}\left(38.5 \pm 0.4^{\circ} \mathrm{C}\right), 13 \mathrm{~h}\left(38.7 \pm 0.3^{\circ} \mathrm{C}\right)$, and 15 $\mathrm{h}\left(38.7 \pm 0.3^{\circ} \mathrm{C}\right)$ before calving in experiments 1,2 , and 3 , respectively. In experiments 1 and 2, VT started to increase again as calving became imminent, whereas it remained at the same level in experiment 3 (Figure 1).

In experiment $1, \mathrm{VT}$ in the last hour before calving $\left(38.7 \pm 0.3^{\circ} \mathrm{C}\right)$ was higher than that during the period from 17 to $19 \mathrm{~h}$ before calving $\left(38.5 \pm 0.4^{\circ} \mathrm{C}\right)$, and lower than that $29 \mathrm{~h}\left(38.9 \pm 0.4^{\circ} \mathrm{C}\right)$ or more before calving $(P<0.05)$. Vaginal temperature in the last hour before calving did not differ from that in the last $16 \mathrm{~h}$ before calving or from that during the period from 20 to $28 \mathrm{~h}$ before calving $(P>0.05$; Figure 1$)$. 
Table 1. Vaginal temperature (mean $\pm \mathrm{SD}$ ) on the $3 \mathrm{~d}$ before and on the day of parturition in experiments 1 ( $\mathrm{n}=30$ primiparous cows), $2(\mathrm{n}=30$ multiparous cows $)$, and $3(\mathrm{n}=25$ multiparous cows $)$

\begin{tabular}{lccc}
\hline & \multicolumn{3}{c}{ Mean vaginal temperature $\left({ }^{\circ} \mathrm{C}\right)$} \\
\cline { 2 - 4 } $\begin{array}{l}\text { Day relative } \\
\text { to calving }\end{array}$ & Experiment 1 & Experiment 2 & Experiment 3 \\
\hline-3 & $39.2 \pm 0.4^{\mathrm{d}}$ & $39.5 \pm 0.3^{\mathrm{c}}$ & $39.3 \pm 0.2^{\mathrm{c}}$ \\
-2 & $39.1 \pm 0.3^{\mathrm{c}}$ & $39.5 \pm 0.3^{\mathrm{c}}$ & $39.3 \pm 0.2^{\mathrm{c}}$ \\
-1 & $38.8 \pm 0.3^{\mathrm{b}}$ & $39.1 \pm 0.3^{\mathrm{b}}$ & $39.0 \pm 0.3^{\mathrm{b}}$ \\
0 & $38.5 \pm 0.3^{\mathrm{a}}$ & $38.8 \pm 0.4^{\mathrm{a}}$ & $38.8 \pm 0.3^{\mathrm{a}}$ \\
\hline
\end{tabular}

${ }^{\mathrm{a}-\mathrm{d}}$ Means within a column with different superscripts differ $(P<0.05)$.

In experiment $2, \mathrm{VT}$ in the last hour before calving $\left(38.9 \pm 0.6^{\circ} \mathrm{C}\right)$ was higher than that during the period from 13 to $15 \mathrm{~h}$ before calving $\left(38.7 \pm 0.3^{\circ} \mathrm{C}\right)$, and lower than that $22 \mathrm{~h}\left(39.2 \pm 0.4^{\circ} \mathrm{C}\right)$ or more before calving $(P<0.05)$. Vaginal temperature in the last hour before calving did not differ from that in the last $12 \mathrm{~h}$ before calving or from that during the period from 16 to $21 \mathrm{~h}$ before calving $(P>0.05$; Figure 1$)$.

In experiment $3, \mathrm{VT}$ in the last hour before calving $\left(38.8 \pm 0.3^{\circ} \mathrm{C}\right)$ was not different from that in the last 21 h before calving $(P>0.05)$, whereas it was lower than that $22 \mathrm{~h}\left(39.0 \pm 0.2^{\circ} \mathrm{C}\right)$ or more before calving $(P<$ 0.05; Figure 1).

Vaginal temperatures exhibited a diurnal rhythm with minima in the morning (0800 to $1300 \mathrm{~h})$ and maxima in the evening (1900 to $2000 \mathrm{~h}$; Figure 2). This rhythm was present from $120 \mathrm{~h}$ before calving until the actual birth process. During the last $48 \mathrm{~h}$, the pattern of the diurnal rhythm was retained, but the range was lower (Figure 2).

Mean RT was lower on the day of calving compared with the last $4 \mathrm{~d}$ prepartum in experiment 2 and last $5 \mathrm{~d}$ in experiment 3 (Table 2). A decrease in VT of 0.2 to $0.4^{\circ} \mathrm{C}$ between a particular time of the day and the same time 24 or $48 \mathrm{~h}$ previously predicted parturition would occur within the next $24 \mathrm{~h}$ in all 3 experiments (Table 3, Figure 3).

A decrease in RT of 0.2 and $0.4^{\circ} \mathrm{C}$ measured either at 0730 or $1700 \mathrm{~h}$ and compared with the same time 24 or $48 \mathrm{~h}$ before, respectively, predicted parturition would occur within the next $24 \mathrm{~h}$ in experiments 2 and 3 (Table 4).

\section{DISCUSSION}

A means to predict the time of the onset of calving accurately would improve the opportunity to supervise calving and potentially reduce the losses subsequent to dystocia of both cows and calves (Mee, 2004; Shah et al., 2006). Continuous monitoring of transition cows remains a challenge regardless of the size of the farm.
Several studies provide evidence that a decrease in body temperature occurs before the onset of calving (Birgel et al., 1994; Lammoglia et al., 1997; Aoki et al., 2005); however, data on the performance of body temperature changes as a predictor are not available. Both $\mathrm{VT}$ and RT were lower on the day of calving compared with the preceding days (Tables 1 and 2). Mean differences in VT and RT ranged from 0.2 to $0.5^{\circ} \mathrm{C}$ (Tables 1 and 2), comparing values on the day of calving with 1 and $2 \mathrm{~d}$ before, respectively, in all 3 experiments. This supports previous studies that demonstrated differences ranging from 0.3 to $0.6^{\circ} \mathrm{C}$ in VT and RT (Birgel et al., 1994; Aoki et al., 2005).

Decreases in VT over both 24- and 48-h intervals were able to distinguish between cows that did and did not calve within $24 \mathrm{~h}$ in all experiments, as demonstrated by areas under the curve (AUC) ranging from 0.77 to $0.87(P<0.01$; Table 3 , Figure 3$)$. Decreases in RT over both 24 - and 48-h intervals were able to distinguish between cows that calved and cows that did not calve within $24 \mathrm{~h}$ (AUC: 0.73 to $0.85, P<0.01$; Table 4). Our data showed that the best test performance was achieved when the change detected in $\mathrm{VT}$ or RT was 0.2 to $0.3^{\circ} \mathrm{C}$ (Tables 3 and 4). This range supports Aoki et al. (2005), who identified a threshold of $0.3^{\circ} \mathrm{C}$, measuring VT, to distinguish between cows that calved and cows that did not calve within 36 to $60 \mathrm{~h}$.

To evaluate the validity of a predictive test, the performance of the test needs to be available (i.e., sensitivity, specificity, positive and negative predictive values). The ROC analysis involves calculating sensitivity and specificity for different thresholds (i.e., differences in body temperature) and plots sensitivity on the $\mathrm{x}$-axis against $(1-$ specificity $)$ on the y-axis. The closer the ROC curve is to the upper left corner, the greater the accuracy of differentiation between cows that will calve within $24 \mathrm{~h}$ and cows that will not calve within $24 \mathrm{~h}$ (Greiner et al., 2000; Figure 3). The area under the ROC curve is greater when the ROC curve is closer to the upper left corner, so AUC is a measure of the overall diagnostic accuracy of the measure tested. If the test could distinguish perfectly between cows that will and 

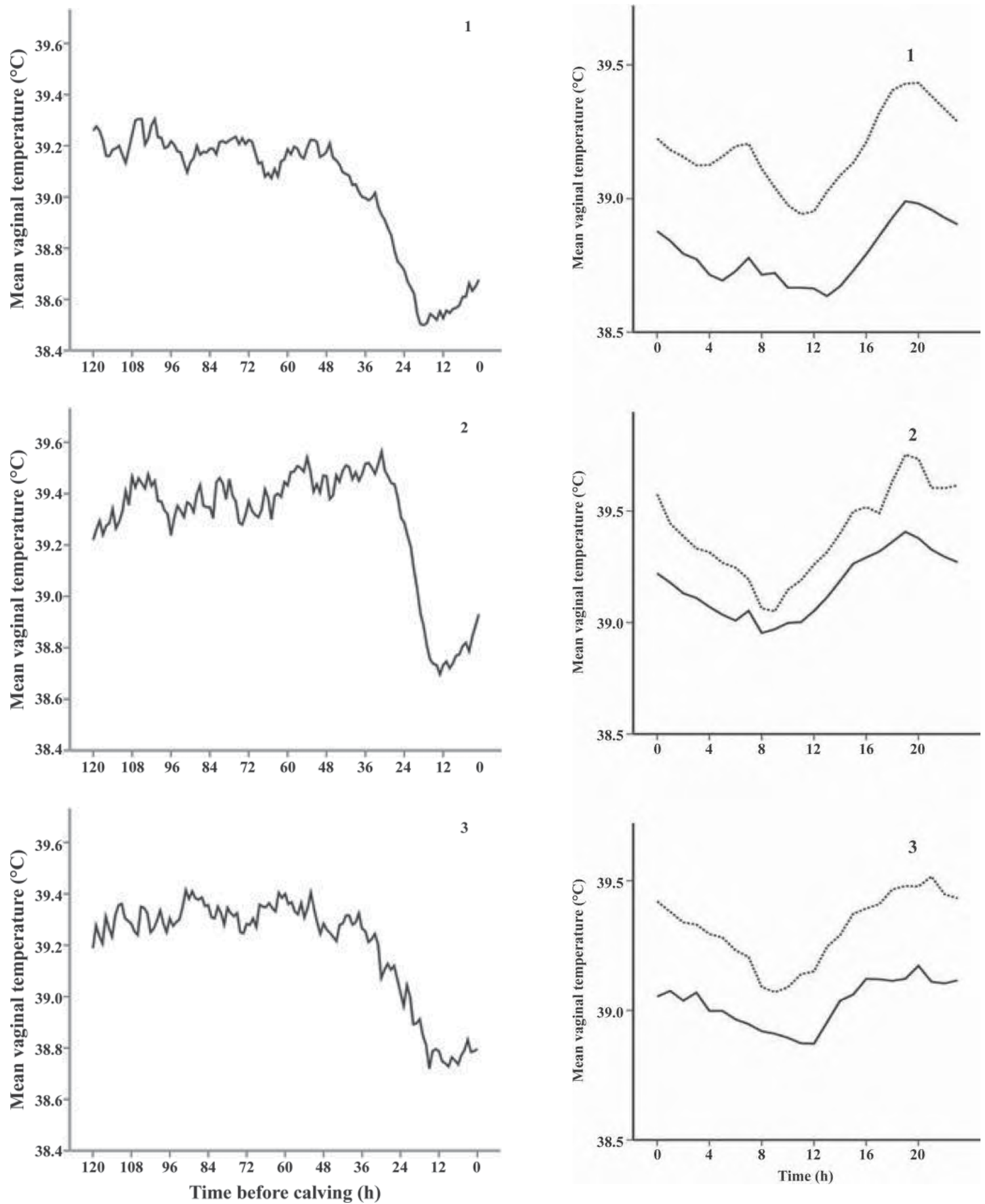

Figure 1. Mean vaginal temperature in the last $120 \mathrm{~h}$ before parturition in experiment 1 ( $\mathrm{n}=30$ primiparous cows), experiment 2 ( $\mathrm{n}$ $=30$ multiparous cows), and experiment 3 ( $\mathrm{n}=25$ multiparous cows).

Figure 2. Diurnal rhythm of vaginal temperature comparing the last $48 \mathrm{~h}(-)$ and 49 to $120 \mathrm{~h}(---)$ before calving in experiment 1 (n $=30$ primiparous cows), $2(\mathrm{n}=30$ multiparous cows $)$, and $3(\mathrm{n}=25$ multiparous cows). 
Table 2. Rectal temperature (mean $\pm \mathrm{SD}$ ) on the $5 \mathrm{~d}$ before and on the day of parturition in experiments 2 ( $\mathrm{n}=30$ multiparous cows) and $3(\mathrm{n}=25$ multiparous cows)

\begin{tabular}{|c|c|c|c|c|}
\hline \multirow{3}{*}{$\begin{array}{l}\text { Day relative } \\
\text { to calving }\end{array}$} & \multicolumn{4}{|c|}{ Mean rectal temperature ${ }^{1}\left({ }^{\circ} \mathrm{C}\right)$} \\
\hline & \multicolumn{2}{|c|}{ Experiment 2} & \multicolumn{2}{|c|}{ Experiment 3} \\
\hline & Morning & Evening & Morning & Evening \\
\hline-5 & $38.9 \pm 0.4^{\mathrm{ac}}$ & $39.3 \pm 0.5^{\mathrm{ab}}$ & $39.0 \pm 0.3^{\mathrm{b}}$ & $39.2 \pm 0.3^{\mathrm{c}}$ \\
\hline-4 & $39.0 \pm 0.6^{\mathrm{bc}}$ & $39.5 \pm 0.4^{\mathrm{b}}$ & $39.0 \pm 0.3^{\mathrm{b}}$ & $39.3 \pm 0.3^{\mathrm{c}}$ \\
\hline-3 & $39.0 \pm 0.3^{\mathrm{bc}}$ & $39.4 \pm 0.3^{\mathrm{b}}$ & $39.0 \pm 0.3^{\mathrm{b}}$ & $39.3 \pm 0.4^{\mathrm{c}}$ \\
\hline-2 & $39.0 \pm 0.3^{\mathrm{bc}}$ & $39.5 \pm 0.5^{\mathrm{b}}$ & $39.0 \pm 0.3^{\mathrm{b}}$ & $39.3 \pm 0.3^{\mathrm{c}}$ \\
\hline-1 & $39.1 \pm 0.4^{\mathrm{bc}}$ & $39.3 \pm 0.6^{\mathrm{b}}$ & $38.9 \pm 0.3^{\mathrm{b}}$ & $39.0 \pm 0.4^{\mathrm{b}}$ \\
\hline 0 & $38.6 \pm 0.4^{\mathrm{a}}$ & $39.0 \pm 0.7^{\mathrm{a}}$ & $38.6 \pm 0.3^{\mathrm{a}}$ & $38.7 \pm 0.3^{\mathrm{a}}$ \\
\hline
\end{tabular}

will not calve, the AUC would be 1, whereas an AUC of 0.5 demonstrates that the test cannot distinguish between the 2 populations at all. Moreover, an AUC of 0.80 means that in $80 \%$ of cases a cow from the positive group (calving within $24 \mathrm{~h}$ ) will have a greater decrease in body temperature than a cow from the negative group (not calving within $24 \mathrm{~h}$; Zweig and Campbell, 1993). Furthermore, from a low $P$-value $(P<0.01)$, we can conclude that the AUC $>0.5$ and therefore, the test can distinguish between the 2 groups.

Although vaginal temperature loggers have been used in livestock research for years, they are not practical for routine use on commercial dairy farms. One reason is that with the technology used in this study data can only be downloaded retrospectively. Therefore, in experiments 2 and 3, RT was measured twice daily and we compared the test performance of rectal thermometry with the continuous VT measurements. Using a decrease in RT within $24 \mathrm{~h}$ gave better test performance in experiment 2 than in experiment 3 (Table 4). When comparing measured temperature values on a 48-h basis, a decrease predicted the onset of parturition more precisely in experiment 3 than in experiment 2 (Table 4). The reasons for these observations remain unclear. It is obvious that body temperature started to decrease later in experiment 2 ( $36 \mathrm{~h}$ before parturition) compared with experiment 3 (48 h before parturition). Furthermore, the decrease in body temperature was more pronounced in experiment 2 than in experiment 3 (Figure 1). Lammoglia et al. (1997) suggested that the decrease in body temperature 48 to $8 \mathrm{~h}$ before parturition may be independent of environmental conditions, but the magnitude of this decrease might be influenced by AT. This could explain why the decrease occurred later but at a faster rate in experiment 2 , in which THI and AT were higher compared with experiments 1 and 3. In our experiments, AT and THI had low correlations with VT $(\mathrm{r}=0.12$ to 0.25$)$. Direct comparisons of the
2 experiments should be regarded with caution because they were not conducted simultaneously; however, important management factors such as nutrition, personnel, handling, and intensity of herd health monitoring were identical during the 2 experiments. Furthermore, cows were housed in the same dry cow and maternity pen in both experiments.

A diurnal VT rhythm was present during the last 120 $\mathrm{h}$ before calving (Figure 2). This finding is in contrast to Lammoglia et al. (1997), who reported the absence of a diurnal rhythm in body temperature from 48 to 8 $\mathrm{h}$ before parturition. 7

Interestingly, VT but not RT started to increase slightly 17 and $13 \mathrm{~h}$ before calving in experiments 1 and 2. Previously, this increase has been described for both RT and VT (Birgel et al., 1994). This difference might be explained by the number of daily measurements in the 2 studies (3 vs. 2). An increase in body temperature approximately $16 \mathrm{~h}$ before parturition was described by Lammoglia et al. (1997) using implanted temperature loggers. The reason for the increase in body temperature remains unclear; however, it is likely associated with increased activity such as frequent changes between standing and lying during the first stage of labor (Metz and Metz, 1987; Wehrend et al., 2006). The first stage of labor begins with dilatation of the cervix and is difficult to determine (Jackson, 2004). It ends with rupture of the chorioallantois in the vagina (Jackson, 2004). We speculate that increased physical activity (i.e., changing between standing and lying, uterine contractions) might explain the increase in body temperature in the last hours before calving. An activity-mediated increase of RT was suggested during estrus in dairy cows (Walton and King, 1986; Suthar et al., 2011). Further research is warranted to evaluate whether the increase in body temperature before parturition is indicative of the beginning of the first stage of labor and whether such information can be used to 
Table 3. Test performance (\%; 95\% CI in parentheses) of incremental decreases in vaginal temperature measured over 24-h and 48-h periods as a predictor of parturition within $24 \mathrm{~h}$ in experiments $1(\mathrm{n}=30$ primiparous cows $), 2(\mathrm{n}=30$ multiparous cows $)$, and $3(\mathrm{n}=25$ multiparous cows $)$

\begin{tabular}{|c|c|c|c|c|c|c|c|}
\hline \multirow{2}{*}{$\begin{array}{l}\text { Temperature } \\
\text { decrease }\end{array}$} & \multirow{2}{*}{$\begin{array}{l}\text { Test } \\
\text { performance }^{1}\end{array}$} & \multicolumn{2}{|c|}{ Experiment 1} & \multicolumn{2}{|c|}{ Experiment 2} & \multicolumn{2}{|c|}{ Experiment 3} \\
\hline & & $24 \mathrm{~h}$ & $48 \mathrm{~h}$ & $24 \mathrm{~h}$ & $48 \mathrm{~h}$ & $24 \mathrm{~h}$ & $48 \mathrm{~h}$ \\
\hline \multirow[t]{4}{*}{$\geq 0.2^{\circ} \mathrm{C}$} & $\mathrm{Se}$ & $76(73-79)$ & $70(68-73)$ & $78(75-81)$ & $79(76-82)$ & $71(67-75)$ & $80(77-83)$ \\
\hline & Sp & $71(69-73)$ & $75(72-77)$ & $79(77-81)$ & $81(79-83)$ & $73(71-75)$ & $73(71-75)$ \\
\hline & $+\mathrm{PV}$ & $47(44-49)$ & $78(75-80)$ & $54(51-57)$ & $59(56-62)$ & $42(38-45)$ & $47(44-50)$ \\
\hline & $-\mathrm{PV}$ & $90(89-91)$ & $67(64-69)$ & $92(91-93)$ & $92(91-93)$ & $90(89-92)$ & $92(91-94)$ \\
\hline \multirow[t]{4}{*}{$\geq 0.3^{\circ} \mathrm{C}$} & Se & $68(65-72)$ & $61(58-63)$ & $71(68-74)$ & $74(70-77)$ & $62(58-66)$ & $72(68-76)$ \\
\hline & Sp & $81(79-83)$ & $85(83-87)$ & $87(85-88)$ & $87(86-89)$ & $83(81-84)$ & $82(80-83)$ \\
\hline & $+\mathrm{PV}$ & $55(51-58)$ & $84(81-86)$ & $62(59-66)$ & $66(63-69)$ & $49(46-53)$ & $54(51-58)$ \\
\hline & $-\mathrm{PV}$ & $89(87-90)$ & $63(61-66)$ & $91(89-92)$ & $91(89-92)$ & $89(87-90)$ & $91(89-92)$ \\
\hline \multirow{6}{*}{$\geq 0.4^{\circ} \mathrm{C}$} & $\mathrm{Se}$ & $57(83-60)$ & $52(49-55)$ & $62(60-65)$ & $67(63-70)$ & $55(51-59)$ & $64(60-67)$ \\
\hline & Sp & $88(87-90)$ & $92(90-93)$ & $92(91-93)$ & $91(88-92)$ & $89(88-91)$ & $90(88-91)$ \\
\hline & $+\mathrm{PV}$ & $62(58-66)$ & $89(86-91)$ & $70(66-74)$ & $72(68-75)$ & $58(54-62)$ & $65(61-68)$ \\
\hline & $-\mathrm{PV}$ & $86(85-87)$ & $61(58-63)$ & $89(87-90)$ & $89(88-90)$ & $88(87-89)$ & $89(88-90)$ \\
\hline & Area under the curve & 0.79 & 0.84 & 0.84 & 0.84 & 0.77 & 0.84 \\
\hline & $(95 \%$ CI $)(P<0.01)$ & $(0.77-0.80)$ & $(0.83-0.86)$ & $(0.83-0.86)$ & $(0.83-0.86)$ & $(0.76-0.79)$ & $(0.82-0.85)$ \\
\hline
\end{tabular}

${ }^{1} \mathrm{Se}=$ sensitivity: proportion of cows that calved within $24 \mathrm{~h}$ and showed a decrease in temperature; $\mathrm{Sp}=$ specificity: proportion of cows that did not calve within $24 \mathrm{~h}$ and did not show a decrease in temperature; $+\mathrm{PV}=$ positive predictive value: proportion of cows that showed a decrease in temperature and calved within $24 \mathrm{~h} ;-\mathrm{PV}=$ negative predictive value: proportion of cows that did not show a decrease and did not calve within $24 \mathrm{~h}$.

Table 4. Test performance (\%; $95 \% \mathrm{CI}$ in parentheses) of incremental decreases in rectal temperature measured either in the morning $(0730 \mathrm{~h})$ or in the evening (1700 $\mathrm{h})$ over 24 -h and 48-h periods as predictors of parturition within $24 \mathrm{~h}$ in experiment $2\left(\mathrm{n}=30\right.$ multiparous cows) and experiment $3\left(\mathrm{n}=25\right.$ multiparous cows) ${ }^{1}$

\begin{tabular}{|c|c|c|c|c|c|c|c|c|c|}
\hline \multirow{3}{*}{$\begin{array}{l}\text { Temperature } \\
\text { decrease }\end{array}$} & \multirow{3}{*}{$\begin{array}{l}\text { Test } \\
\text { performance }\end{array}$} & \multicolumn{4}{|c|}{ Experiment 2} & \multicolumn{4}{|c|}{ Experiment 3} \\
\hline & & \multicolumn{2}{|c|}{$24 \mathrm{~h}$} & \multicolumn{2}{|c|}{$48 \mathrm{~h}$} & \multicolumn{2}{|c|}{$24 \mathrm{~h}$} & \multicolumn{2}{|c|}{$48 \mathrm{~h}$} \\
\hline & & Morning & Evening & Morning & Evening & Morning & Evening & Morning & Evening \\
\hline \multirow[t]{4}{*}{$\geq 0.2^{\circ} \mathrm{C}$} & $\mathrm{Se}$ & $77(60-90)$ & $77(60-90)$ & $66(47-81)$ & $74(57-88)$ & $48(28-69)$ & $56(35-76)$ & $76(55-91)$ & $84(64-95)$ \\
\hline & $\mathrm{Sp}$ & $82(74-88)$ & $77(69-84)$ & $81(74-87)$ & $75(65-83)$ & $83(74-90)$ & $77(70-83)$ & $78(68-86)$ & $74(63-83)$ \\
\hline & $+\mathrm{PV}$ & $55(40-69)$ & $49(35-63)$ & $44(29-59)$ & $49(35-63)$ & $40(23-59)$ & $28(16-43)$ & $48(32-64)$ & $48(33-63)$ \\
\hline & $-\mathrm{PV}$ & $93(86-97)$ & $92(85-97)$ & $91(85-96)$ & $90(82-95)$ & $87(79-93)$ & $92(86-96)$ & $93(84-97)$ & $94(86-98)$ \\
\hline \multirow[t]{4}{*}{$\geq 0.3^{\circ} \mathrm{C}$} & $\mathrm{Se}$ & $69(51-83)$ & $69(51-83)$ & $50(32-68)$ & $60(42-76)$ & $44(24-65)$ & $44(24-65)$ & $64(43-82)$ & $76(55-91)$ \\
\hline & $\mathrm{Sp}$ & $86(79-92)$ & $87(80-92)$ & $88(82-93)$ & $83(75-90)$ & $88(80-93)$ & $88(82-93)$ & $91(83-96)$ & $82(72-89)$ \\
\hline & $+\mathrm{PV}$ & $59(42-74)$ & $60(43-75)$ & $49(31-66)$ & $54(37-70)$ & $46(26-67)$ & $37(20-56)$ & $64(43-82)$ & $54(37-71)$ \\
\hline & $-\mathrm{PV}$ & $90(84-95)$ & $91(84-95)$ & $89(82-93)$ & $86(78-92)$ & $87(79-93)$ & $91(85-95)$ & $91(83-96)$ & $92(84-97)$ \\
\hline \multirow{5}{*}{$\geq 0.4^{\circ} \mathrm{C}$} & $\mathrm{Se}$ & $51(34-69)$ & $57(39-74)$ & $47(29-65)$ & $57(39-74)$ & $40(21-61)$ & $44(24-65)$ & $56(35-76)$ & $52(31-72)$ \\
\hline & $\mathrm{Sp}$ & $90(83-95)$ & $89(83-94)$ & $89(83-94)$ & $85(77-91)$ & $94(88-98)$ & $88(82-93)$ & $97(91-99)$ & $92(84-97)$ \\
\hline & $+\mathrm{PV}$ & $60(41-77)$ & $61(42-77)$ & $50(31-69)$ & $56(38-72)$ & $63(36-85)$ & $37(20-56)$ & $82(57-96)$ & $65(41-85)$ \\
\hline & $-\mathrm{PV}$ & $87(79-92)$ & $88(81-93)$ & $88(82-93)$ & $86(78-92)$ & $87(79-92)$ & $91(85-95)$ & $89(82-95)$ & $87(79-93)$ \\
\hline & $\begin{array}{l}\text { Area under the curve } \\
(95 \% \text { CI })(P<0.01)\end{array}$ & $\begin{array}{l}0.84 \\
(0.77-0.89)\end{array}$ & $\begin{array}{l}0.83 \\
(0.77-0.89)\end{array}$ & $\begin{array}{l}0.82 \\
(0.75-0.87)\end{array}$ & $\begin{array}{l}0.79 \\
(0.72-0.86)\end{array}$ & $\begin{array}{l}0.73 \\
(0.64-0.80)\end{array}$ & $\begin{array}{l}0.78 \\
(0.72-0.84)\end{array}$ & $\begin{array}{l}0.87 \\
(0.80-0.92)\end{array}$ & $\begin{array}{l}0.85 \\
(0.77-0.91)\end{array}$ \\
\hline
\end{tabular}

$\mathrm{Se}=$ sensitivity: proportion of cows that calved within $24 \mathrm{~h}$ and showed a decrease in temperature; $\mathrm{Sp}=$ specificity: proportion of cows that did not calve within $24 \mathrm{~h}$ and did not show a decrease in temperature; $+\mathrm{PV}=$ positive predictive value: proportion of cows that showed a decrease in temperature and calved within $24 \mathrm{~h} ;-\mathrm{PV}=\mathrm{negative}$ predictive 

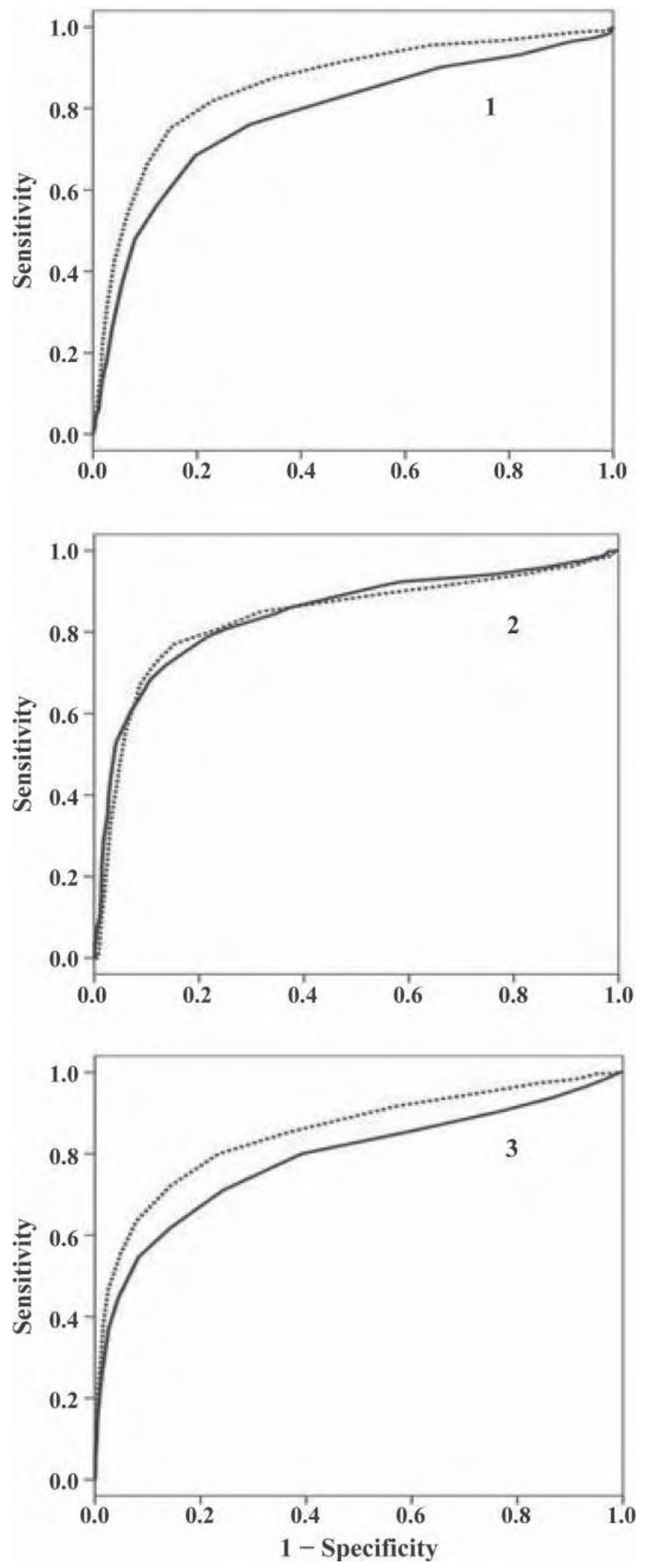

Figure 3. Receiver-operating characteristic (ROC) analysis of the onset of calving within $24 \mathrm{~h}$ after a decrease in vaginal temperature based on a 24-h (-) and a 48-h (---) difference in each experiment. improve dry cow management and to time calving assistance more precisely. Future work in the area should investigate whether improvements in prediction of the day of calving can result in interventions that provide benefits, and whether these benefits can be provided on farm in a cost-effective manner.

\section{CONCLUSIONS}

An accurate predictor of parturition might help to focus observation and provide obstetrical assistance if required. Dairy cows exhibit a distinctive decrease in body temperature approximately $48 \mathrm{~h}$ before calving. Detecting this decrease can provide additional information about the onset of calving. Continuous measures of body temperature were a good tool to detect and visualize this decrease; however, the technology used in this study only allowed retrospective downloading of the temperature data and is not practical for implementation on commercial dairy farms. Intermittent monitoring of rectal temperature provided valuable information about the onset of calving, in addition to the traditional signs.

\section{ACKNOWLEDGMENTS}

We thank the staff of the University of British Columbia Dairy Education and Research Centre and the University's Animal Welfare Program (Vancouver, British Columbia, Canada). Furthermore, we greatly appreciate the kind cooperation of the farm personnel on the dairy farm in Germany. The authors are particularly grateful to Marina von Keyserlingk and Dan Weary from the Animal Welfare Program, UBC, for an outstanding collaboration.

\section{REFERENCES}

Aoki, M., K. Kimura, and O. Suzuki. 2005. Predicting time of parturition from changing vaginal temperature measured by data-logging apparatus in beef cows with twin fetuses. Anim. Reprod. Sci. $86: 1-12$.

Birgel, E. H., Jr., E. Grunert, and J. A. Soares. 1994. The preliminary stage of labor in cattle in relation to the clinical signs of labor and the course of progesterone secretion for the prediction of the calving time. Dtsch. Tierarztl. Wochenschr. 101:355-359.

Burfeind, O., M. A. G. von Keyserlingk, D. M. Weary, D. M. Veira, and W. Heuwieser. 2010. Short communication: Repeatability of measures of rectal temperature in dairy cows. J. Dairy Sci. 93:624-627.

Canadian Council on Animal Care. 1993. Guide to the Care and Use of Experimental Animals. Vol.1. E. D. Olfert, B. M. Cross, and A. A. McWilliam, ed. CCAC, Ottawa, Ontario, Canada.

Cooper-Prado, M. J., N. M. Long, E. C. Wright, C. L. Goad, and R. P. Wettemann. 2011. Relationship of ruminal temperature with parturition and estrus of beef cows. J. Anim. Sci. 89:1020-1027.

Greiner, M., D. Pfeiffer, and R. D. Smith. 2000. Principles and practical application of the receiver-operating characteristic analysis for diagnostic tests. Prev. Vet. Med. 45:23-41. 
Gundelach, Y., K. Essmeyer, M. K. Teltscher, and M. Hoedemaker. 2009. Risk factors for perinatal mortality in dairy cattle: Cow and foetal factors, calving process. Theriogenology 71:901-909.

Hellmann, K., and I. Radeloff. 2000. International Cooperation on Harmonisation of Technical Requirements for Registration of Veterinary Medicinal Products. VICH, Brussels, Belgium.

Jackson, P. G. 2004. Handbook of Veterinary Obstetrics. 2nd ed. W. B. Saunders, New York, NY.

Kendall, P. E., P. P. Nielsen, J. R. Webster, G. A. Verkerk, R. P. Littlejohn, and L. R. Matthews. 2006. The effects of providing shade to lactating dairy cows in a temperate climate. Livest. Sci. 103:148-157.

Kendall, P. E., C. B. Tucker, D. E. Dalley, D. A. Clark, and J. R. Webster. 2008. Milking frequency affects the circadian body temperature rhythm in dairy cows. Livest. Sci. 117:130-138.

Kendall, P. E., G. A. Verkerk, J. R. Webster, and C. B. Tucker. 2007. Sprinklers and shade cool cows and reduce insect-avoidance behavior in pasture-based dairy systems. J. Dairy Sci. 90:3671-3680.

Kendall, P. E., and J. R. Webster. 2009. Season and physiological status affects the circadian body temperature rhythm of dairy cows. Livest. Sci. 125:155-160.

Lammoglia, M. A., R. A. Bellows, R. E. Short, S. E. Bellows, E. G. Bighorn, J. S. Stevenson, and R. D. Randel. 1997. Body temperature and endocrine interactions before and after calving in beef cows. J. Anim. Sci. 75:2526-2534.

Lombard, J. E., F. B. Garry, S. M. Tomlinson, and L. P. Garber. 2007. Impacts of dystocia on health and survival of dairy calves. J. Dairy Sci. 90:1751-1760.

Mee, J. F. 2004. Managing the dairy cow at calving time. Vet. Clin. North Am. Food Anim. Pract. 20:521-546.

Mee, J. F. 2008. Prevalence and risk factors for dystocia in dairy cattle: A review. Vet. J. 176:93-101.

Metz, J., and J. H. M. Metz. 1987. Behavioural phenomena related to normal and difficult deliveries in dairy cows. Neth. J. Agric. Sci. 35:87-101.

Meyer, C. L., B. J. Berger, and K. J. Koehler. 2001. Phenotypic trends in incidence of stillbirth for Holsteins in the United States. J. Dairy Sci. 84:515-523.
Piccione, G., G. Caola, and R. Refinetti. 2003. Daily and estrous rhythmicity of body temperature in domestic cattle. BMC Physiol. 3:7.

Rajala, P. J., and Y. T. Gröhn. 1998. Effects of dystocia, retained placenta, and metritis on milk yield in dairy cows. J. Dairy Sci. 81:3172-3181.

Shah, K. D., T. Nakao, and H. Kubota. 2006. Plasma estrone sulphate (E1S) and estradiol-17beta (E2beta) profiles during pregnancy and their relationship with the relaxation of sacrosciatic ligament, and prediction of calving time in Holstein-Friesian cattle. Anim. Reprod. Sci. 95:38-53.

Suthar, V. S., O. Burfeind, J. S. Patel, A. J. Dhami, and W. Heuwieser. 2011. Body temperature around induced estrus in dairy cows. J. Dairy Sci. 94:2368-2373.

Tenhagen, B. A., A. Helmbold, and W. Heuwieser. 2007. Effect of various degrees of dystocia in dairy cattle on calf viability, milk production, fertility and culling. J. Vet. Med. A Physiol. Pathol. Clin. Med. 54:98-102.

Vickers, L. A.. O. Burfeind, M. A. G. von Keyserlingk, D. M. Veira, D. M. Weary, and W. Heuwieser. 2010. Technical note: Comparison of rectal and vaginal temperatures in lactating dairy cows. J. Dairy Sci. 93:5246-5251.

Walton, J. S., and G. J. King. 1986. Indicators of estrus in Holstein cows housed in tie stalls. J. Dairy Sci. 69:2966-2973.

Webster, J. R., M. Stewart, A. R. Rogers, and G. A. Verkerk. 2008. Assessment of welfare from physiological and behavioural responses of New Zealand dairy cows exposed to cold and wet conditions. Anim. Welf. 17:19-26.

Wehrend, A., E. Hofmann, K. Failing, and H. Bostedt. 2006. Behaviour during the first stage of labour in cattle: Influence of parity and dystocia. Appl. Anim. Behav. Sci. 100:164-170.

Zweig, M. H., and G. Campbell. 1993. Receiver-operating characteristic (ROC) plots: A fundamental evaluation tool in clinical medicine. Clin. Chem. 39:561-577. 